\title{
Optimization for Tensile Strength of Sisal Fiber, Glass Fiber and Alumina- Based Hybrid Composite using Taguchi Technique
}

\author{
Veenapani $\mathrm{R}^{\# 1}$, B M Rajaprakash² , Akash $\mathbf{M}^{22}$
}

\#1PG Scholar, Mechanical Engineering, UVCE, Bangalore University, Bengaluru, Karnataka, India. \#2Professor, Mechanical Engineering, UVCE, Bangalore University, Bengaluru, Karnataka, India \#PG Scholar, Mechanical Engineering, UVCE, Bangalore University, Bengaluru, Karnataka, India

\section{ABSTRACT}

\section{Article Info}

Volume 8, Issue 5

Page Number : 299-308

\section{Publication Issue}

September-October-2021

\section{Article History}

Accepted : 01 Oct 2021

Published : 07 Oct 2021
Natural fibers composite play an important role in making eco-friendly products. The present investigation has been made to find tensile strength of hybrid composites fabricated using optimal composition of sisal fiber, glass fiber and alumina. Multi-response optimization has been carried out. The compositions of reinforcements namely sisal fiber, glass fiber and alumina in hybrid composite were prepared by Hand-layup technique. Sisal fiber of $20 \mathrm{Wt} . \%, 30 \mathrm{Wt} . \%$ and 40 Wt. $\%$ are chopped into $10 \mathrm{~mm}$ length, Glass fiber of $20 \mathrm{Wt} . \%, 30 \mathrm{Wt} . \%$ and 40 Wt. $\%$ are $10 \mathrm{~mm}$ length and alumina particles of $2 \mathrm{Wt} . \%, 3 \mathrm{Wt} . \%$ and $4 \mathrm{Wt} . \%$ are compositions of reinforcement were chosen according to orthogonal array as Taguchi technique(L9). The results have been verified through confirmatory experiments. Experimentations were carried out with the different composition based on L9 process parameters. Based on the experimental observations the maximum ultimate tensile strength was found to be $37.87 \mathrm{MPa}$ for optimised input parameters as $20 \%$ of sisal fiber, $30 \%$ of glass fiber and $3 \%$ of alumina.

Keywords: Sisal Fiber, Glass Fiber, Alumina, Tensile strength, Taguchi method, ANOVA.

\section{INTRODUCTION}

The present-day society is dealing with some of demanding situations associated with health, sustainability, and environmental protection. Inevitably, the need of designing and growing new useful substances that would enhance the nice of lifestyles and cause the improvement of superior technology is of paramount importance. During the beyond decades, polymer technology has strongly been getting into the sphere of organic-inorganic hybrids, aiming to mix the residences of polymers with the ones of inorganic additives. The former consists of ease of processing, light-weight, flexibility, extraordinarily excessive versatility in substances' layout in regard to the structural and architectural traits and therefore in substances' residences. Inorganic substances showcase advanced thermal and mechanical conduct in addition to precise optical, electrical, catalytic, and magnetic residences, particularly while the ones are characterized with the aid of using nanoscale dimensions. It is a truism that technological improvement relies upon on advances withinside the subject of substances.

Nature is complete of examples in which the concept of composite substances is used. The coconut palm leaf, 
for instance, is largely a cantilever bit the usage of the idea of fiber reinforcement. Wood is a fibrous composite: cellulose fibers in a lignin matrix. The cellulose fibers have excessive tensile power however are very flexible (i.e., low stiffness), even as the lignin matrix joins the fibers and furnishes the stiffness. Weiner and Wagner (1998) deliver an excellent description of shape and residences of bone. For descriptions of the shape-feature relationships withinside the plant and animal kingdoms, the reader is noted Elices (2000) and Wainwright et al. (1982) [1].

The new composite material often displays many beneficial characteristics; in many cases, composites are stronger, of lower density, or less costly in comparison to established materials. Commonly, composites consist of two or more different components forming regions sufficiently large to be considered as continua; the basic components are usually strongly fused at the interface. A variety of both natural and synthetic materials confirm to this picture, such as mortar and concrete, reinforced rubber, alloys, polymers containing fillers, aligned and chopped fiber composites, porous and cracked media, polycrystalline (metal) aggregates, and others [2].

Composite materials are composed of individual basic materials, which are referred to as so-called constituent materials. Two main categories of constituent materials are distinguished: the matrix ("binder") and the reinforcement. At least one representative from each category is needed to create a composite. The matrix phase embeds, surrounds, and supports the reinforcements by preserving their relative locations. The reinforcements contribute their specific physical and mechanical assets, thus enhancing the properties of the matrix. The achieved synergism between the two phases generates material properties not observed for the individual constituent materials, while the unlimited number of binders and reinforcements enables the designer to develop optimum combinations, thus creating tailor-made composites [3].

Particle reinforced composites are subclassified as Large-particle and dispersion-strengthened composites. The distinction between these is based upon reinforcement or strengthening mechanism. The term "large" is used to indicate that particle-matrix interactions cannot be treated on the atomic or molecular level; rather, continuum mechanics is used. For most of these composites, the particulate phase is harder and stiffer than the matrix. These reinforcing particles tend to restrain movement of the matrix phase in the vicinity of each particle. In essence, the matrix transfers some of the applied stress to the particles, which bear a fraction of the load. The degree of reinforcement or improvem of mechanical behavior depends on strong bonding at the matrix-particle interface. For dispersion-strengthened composites, particles are normally much smaller, with diameters between 0.01 and $0.1 \mathrm{~m}$ (10 and $100 \mathrm{~nm})$. Particlematrix interactions that lead to strengthening occur on the atomic or molecular level [4-5].

Glass fibers (GFs) are most widely used among all the synthetic fibers as they offer excellent strength and durability, thermal stability, resistance to impact, chemical, friction, and wear properties. However, the machining of glass fiber-reinforced polymers (GFRPs) is relatively slow, challenging, and shows reduced tool life while working on conventional machining systems. GFs also carry the disadvantage of disposal at the end of their service life. However, in some applications, more stiffness is required, so carbon fibers $(\mathrm{CFs})$ are employed instead of GFs. Although some of the other types of synthetic fibers like aramid, basalt, polyacrylonitrile (PAN-F), polyethylene terephthalate (PET-F), or polypropylene fibers (PP-F) offer some advantages, they are rarely used in thermoplastic shortfiber-reinforced polymers (SFRP); they have been used for specific applications where their desired properties are applicable [6-9].

Mukherjee and Satyanarayana in this work they studied the properties of Sisal fiber, such as tensile properties (ultimate tensile strength (UTS), initial modulus (YM), average modulus (AM), and percent elongation at break) of sisal fibres as a function of fiber diameter, test length, and test speed. The result revealed that UTS, YM, AM and percent elongation lie in the range 530 to $630 \mathrm{MPa}$, 17 to $22 \mathrm{GPa}, 9.8$ to $16.5 \mathrm{GPa}$ and 3.64 to $5.12 \%$ respectively for fibres of diameters ranging between 100 and $300 \mu \mathrm{m}$. No significant variation of mechanical properties with change in diameter of the fibres was observed [9]. Munawar et al. found that, the sisal fibre has a tensile strength of $375 \pm 38 \mathrm{MPa}$, specific tensile strength of 493MPa, Young's modulus of $9.1 \pm 0.8 \mathrm{GPa}$, 
specific young's modulus of $12.1 \mathrm{GPa}$, and toughness of $10.7 \pm 1.2 \mathrm{MPa}[10]$.

Abilash and Sivapragash made successful study on sisal and jute composite. In this Sisal and Jute fibers were fabricated and reinforced with polypropylene composite using compression molding technique. At the end, the author conclude that sisal based polypropylene composite has higher tensile strength than jute based composite and jute based polypropylene composite has higher compressive strength than sisal-based polypropylene [11].

Kuruvilla et al. He found that Sisal fibres have good potential as reinforcements in polymer (thermoplastics, thermosets and rubbers) composites. Due to the low density and high specific properties of sisal fibres, composites based on these fibres may have very good implications in the automotive and transportation industry [12].

Andressa Cecília Milanese et al. Here Sisal/polyurethane composites with 44 wt. (\%) of reinforcement and sisal/phenolic composites with $33 \mathrm{wt}$. (\%) of reinforcement were prepared by compress molding technique at room temperature. Tensile tests of resins and composites were performed using a universal machine and results were compared as follows, thermal treatment of sisal fabric reinforcement applied before molding the polyurethane composite was suitable when considering its tensile behavior, once the treatment increases notable tensile strength [13].

M. Ramesh et al worked-on glass -sisal- jute fiber reinforced epoxy composites and their aim of the study is to evaluate mechanical properties such as tensile and tensile properties of hybrid glass fiber-sisal/jute reinforced epoxy composites. Microscopic examinations are carried out to analyze the interfacial characteristics of materials, internal structure of the fractured surfaces and material failure morphology by using Scanning Electron Microscope (SEM). The results indicated that the incorporation of sisal fiber with GFRP exhibited superior properties than the jute fiber reinforced GFRP composites in tensile properties and jute fiber reinforced GFRP composites performed better in tensile properties [14].
In the present work it has been proposed to develop a hybrid composite composing of sisal fiber, glass fiber and Alumina with an intention to obtain improved mechanical properties such as tensile and tensile strength. They are some following objectives of the projects are: 1 . The main objective of this dissertation work is to prepare composite material with sisal fiber, glass fiber with Alumina that composite material is to replace for roofing and in automotive parts. 2. The natural fiber used to make roofing and automotive parts are sisal fiber and glass fiber with Alumina and to present a survey of composite material with natural fiber as ingredient, and to indicate their typical properties and functions. 3. The combination of natural fiber and synthetic fiber with particle reinforced are prepared through various processes and are subjected to various mechanical tests. This test results are compared to that of only natural or synthetic fiber[15-17].

\section{METHODS AND MATERIAL}

\subsection{MATERIALS}

The reinforcement materials and matrix materials used in the present research are tabulated in Table 1.

Table 1: Specifications of the materials used

\begin{tabular}{|l|l|c|}
\hline $\begin{array}{l}\text { SI } \\
\text { No }\end{array}$ & Materials & Density \\
\hline 01 & $\begin{array}{l}\text { Epoxy resin LY 556 } \\
\text { Hardener HY 951 }\end{array}$ & $1.15 \mathrm{~g} / \mathrm{cm}^{3}$ \\
\hline 02 & $\begin{array}{l}\text { Aluminum oxide calcined } \\
99 \% \text { extra pure }\end{array}$ & $3.95 \mathrm{~g} / \mathrm{cm}^{3}$ \\
\hline 03 & Glass Fiber & $2.54 \mathrm{~g} / \mathrm{cm}^{3}$ \\
\hline 04 & Sisal Fiber & $1.45 \mathrm{~g} / \mathrm{cm}^{3}$ \\
\hline
\end{tabular}

\subsection{OPTIMIZATION OF REINFORCEMENT A. DESIGN OF EXPERIMENTS}

The determination of design factors is the critical stage for the design of trials. There are many outline factors, for example, filler content, load, speed, sliding distances and so forth, which will influence the test consequences of friction coefficient and weight reduction. In a systematically designed set of experiments, having included parameters of importance are changed for a specified range, this is good approach to gain systematic data. In Mathematical language, such a full set of experiments is set to give required results. In such cases number of experiments and resources essential are possibly large. Many times, researchers decide to carry 
out a subset of the total set of experiments to save efforts and money. Even though, it does not simply provide itself to understanding of art behind the phenomenon. The investigation is not so simple and obvious effects of different parameters on the practical data are not readily noticeable.

\section{B. EXPERIMENTAL DESIGN}

The steps applied for Taguchi optimization in this study are as follows.

$>$ Select noise and control factors.

$>$ Select Taguchi orthogonal array.

$>$ Conduct Experiments

$>$ Tensile Strength Measurement

$>$ Analyse result (signal to noise ration)

$>$ Predict optimum performance

$>$ Confirmation Experiment

\section{SIGNAL TO NOISE RATION}

$\mathrm{S} / \mathrm{N}$ ratio is used as measurable value instead of standard deviation due to the fact that, as the mean decreases, the standard deviation also decreases and vice versa. In other words, the standard deviation cannot be minimized first and mean brought to the target. In practice, the target mean value may change during the process development. Two of the application in which the concept of $\mathrm{S} / \mathrm{N}$ ratio is useful are the improvement of quality through variability reduction and the improvement of measurement. The $\mathrm{S} / \mathrm{N}$ ration characteristics can be divided into three categories given by Equation.

$>$ Larger is the better characteristics $\mathrm{S} / \mathrm{N}=-10 * \log$ $\left(\Sigma\left(1 / Y^{2}\right) / n\right.$.

$>$ Nominal is the better characteristics $\mathrm{S} / \mathrm{N}=-10$

$* \log \left(\sigma^{2}\right)$.

$>$ Smaller is the better characteristics $\mathrm{S} / \mathrm{N}=-10$

$\left.* \log \left(\Sigma\left(\mathrm{Y}^{2}\right) / \mathrm{n}\right)\right)$

Where ' $n$ ' is the number of trials and ' $y$ ' is the experimental value.

\subsection{TAGUCHI METHOD}

Taguchi is an effective tool in designing of high-quality systems. Taguchi method is to enhance the procedure parameter to accomplish best quality execution, with relatively low cost. Conventional methods are complex in nature and difficult to use and time consuming also high cost. On the off chance that the quantity of process parameter increments, there are lot of trials must be directed to get the optimized parameter. To make the undertaking simple, Taguchi technique utilizes plan of orthogonal array (OA) to study the procedure parameter with modest number of tests.

The Taguchi technique includes lessening the variety in a procedure through powerful plan of investigations. The general goal of the strategy is to deliver high quality product requiring little to no effort to the producer. The Taguchi strategy was created by Dr. Genichi Taguchi, a technique for planning trials to research how extraordinary parameters influence the mean and fluctuation of process execution qualities that characterizes how well the procedure is working. The Taguchi technique gives the $\mathrm{S} / \mathrm{N}$ proportion as the execution record to assess the characteristics of the product or process. It tends to be effortlessly characterized as the proportion of the mean (signal) to the standard deviation (noise) by $\mathrm{S} / \mathrm{N}$ proportion. The $\mathrm{S} / \mathrm{N}$ proportions might be relied upon the specific kind of performance characteristics, including smaller isbetter or larger is-better. The process parameters of reinforcements in different level as shown in Table 2. The taguchi design for fabrication is designed in MINITAB 19 is as shown in Table 3.

Table 2: Process parameters

\begin{tabular}{|l|l|l|l|}
\hline $\begin{array}{l}\text { Process } \\
\text { parameters }\end{array}$ & Level 1 & Level 2 & Level 3 \\
\hline Sisal fiber \% (A) & 20 & 30 & 40 \\
\hline $\begin{array}{l}\text { Glass fiber \% } \\
(\mathrm{B})\end{array}$ & 20 & 30 & 40 \\
\hline Al2O3 \% (C) & 2 & 3 & 4 \\
\hline
\end{tabular}

Table 3: Taguchi design for fabrication

\begin{tabular}{|l|l|l|l|}
\hline EXP NO. & Sisal \% & Glass \% & Al2O3 \% \\
\hline 1 & 20 & 20 & 2 \\
\hline 2 & 20 & 30 & 3 \\
\hline 3 & 20 & 40 & 4 \\
\hline 4 & 30 & 20 & 3 \\
\hline 5 & 30 & 30 & 4 \\
\hline 6 & 30 & 40 & 2 \\
\hline 7 & 40 & 20 & 4 \\
\hline 8 & 40 & 30 & 2 \\
\hline 9 & 40 & 40 & 3 \\
\hline
\end{tabular}




\subsection{HAND LAY-UP TECHNIQUE}

The manufacturing process known as 'hand layup' involves manually laying down individual layers or 'plies' of a form of reinforcement known as 'prepreg' as shown in Figure 1. This consists of thousands of fibers, which are pre-impregnated with resin and bundled into tows and arranged either in a single unidirectional ply or woven together. Epoxy resin with hardener was chosen in a ratio as per process parameters by weight for fabrication of composite. Chopped sisal fibers was used to prepare specimen. The polymers composites are fabricated by hand lay-up technique. Composite samples with various fiber loading were made and subjected to post curing for 24 hours at room temperature. This technique is best suited for thermosetting polymer -based composites. Any combination of fibers and matrix material can be used in this method and also capital and infrastructural requirement are less than the other methods. some of the drawbacks we face in this technique are like uniform distribution of resin inside fabric is not possible, formation of voids in the laminates, quality of final product depends upon skills of labour. One of the most important drawbacks we face in this method is less production rate and difficult to get high volume fraction of reinforcement. The process is suitable for fabrication of wind turbine blades, boat and architectural moulding etc. The method implemented in the fabrication of sisal fiber, glass fiber and Alumina powder-based hybrid composite is hand lay-up technique and it is a closed molding technique done manually.

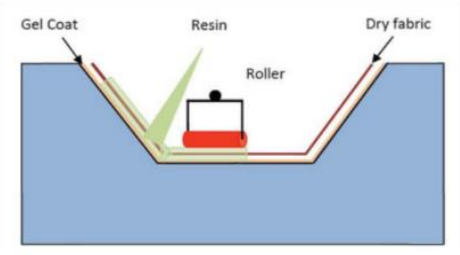

Figure 1: Hand layup technique

\subsection{TENSILE TEST}

Tensile strength indicates the ability of a composite material to withstand forces that pull it apart as well as the capability of the material to stretch prior to failure. The commonly used specimen for tensile test is the dog-bone type which is as shown in Figure 2. During the test a uni-axial load is applied through both the ends of the specimen. The tensile tests were conducted according to the ASTM D638 standard on $100 \mathrm{KN}$ Kalpak computerized universal testing machine as shown in Figure 3. The test was conducted with a cross head speed of $10 \mathrm{~mm} / \mathrm{min}$ and test was carried out at room temperature. (Make: Kalpak Instruments and Controls, Pune, Model: KIC - 2 - 1000 - C and maximum loading capacity: $100 \mathrm{KN}$ ).

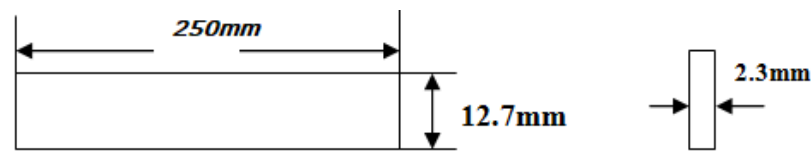

Figure 2: Tensile test specimen dimension

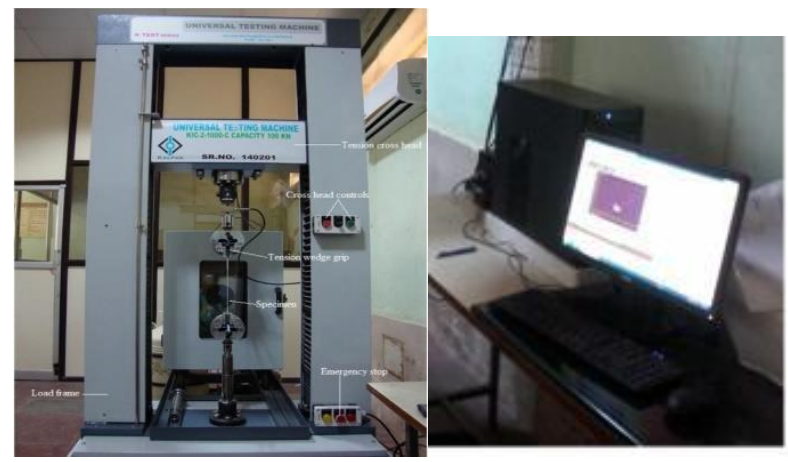

Figure 3: Computerized universal testing machine

Composite laminates fabricated as per the stacking sequence listed in Table. 3 were used to estimate tensile properties. The test specimens used for tensile test as per ASTM D638 standard are as shown in Figure 4.

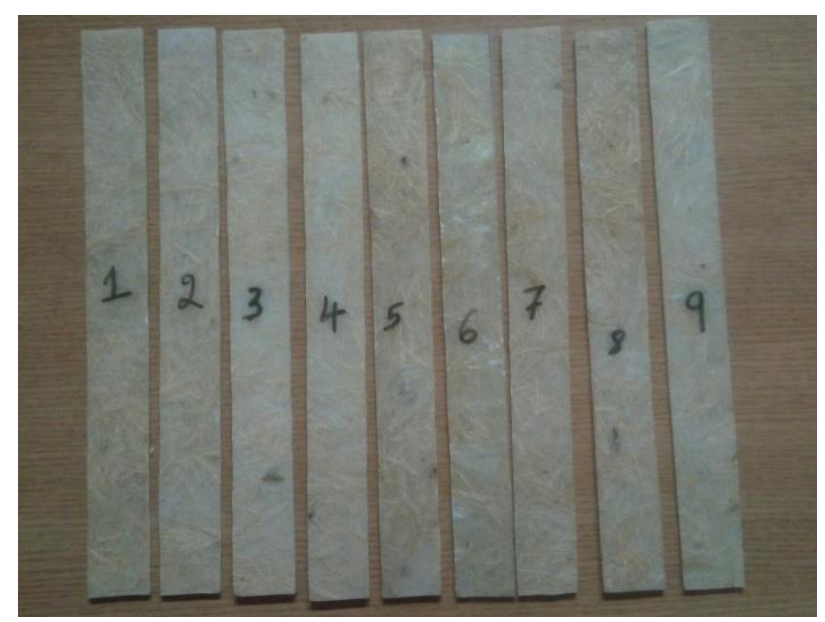

Figure 4: Tensile test specimen samples

\section{RESULTS AND DISCUSSION}

\section{A. Optimum Composition of Reinforcements of Composite with Tensile strength.}


A new class of hybrid composite comprising of sisal fiber, glass fiber and alumina powder is being developed by Hand layup technique using epoxy resin as the matrix material. The optimum composition of reinforcement is determined and added for maximum tensile strength of the hybrid composite developed. After determining the range of reinforcements from compliance testing, using Design of Experiments L9 Orthogonal array was selected. The results of experiments conducted are tabulated below, Table 4 shows the tensile strength and signal to noise ration of hybrid composite for different combination of volume fractions of the reinforcements used. After determining the range of reinforcements from compliance testing, using Design of Experiments L9 Orthogonal array was selected. The optimum composition of reinforcement of composition for maximum tensile strength as shown in Table 5.

Table 4: Experimental results and their calculated $\mathrm{S} / \mathrm{N}$ ratios

\begin{tabular}{|c|c|c|c|c|c|}
\hline Exp. Runs Controllable process & \multicolumn{2}{l|}{$\begin{array}{l}\text { Experimental } \\
\text { parameters }\end{array}$} & $\begin{array}{l}\text { S/N ratios } \\
\text { results }\end{array}$ \\
\cline { 2 - 6 } & $\begin{array}{l}\text { Sisal results } \\
\text { fiber }\end{array}$ & $\begin{array}{l}\text { Glass } \\
\text { fiber }\end{array}$ & Alumina & $\begin{array}{l}\text { Tensile } \\
\text { strength Mpa }\end{array}$ & $\begin{array}{l}\text { Tensile } \\
\text { strength }\end{array}$ \\
\hline 1 & 20 & 20 & 2 & 29.56 & 29.4141 \\
\hline 2 & 20 & 30 & 3 & 37.87 & 31.5659 \\
\hline 3 & 20 & 40 & 4 & 30.47 & 29.6774 \\
\hline 4 & 30 & 20 & 3 & 28.51 & 29.0999 \\
\hline 5 & 30 & 30 & 4 & 30.33 & 29.6374 \\
\hline 6 & 30 & 40 & 2 & 25.86 & 28.2526 \\
\hline 7 & 40 & 20 & 4 & 17.24 & 24.7307 \\
\hline 8 & 40 & 30 & 2 & 25.63 & 28.1750 \\
\hline 9 & 40 & 40 & 3 & 31.29 & 29.9081 \\
\hline
\end{tabular}

Table 5: Optimum Composition of Reinforcements of Composite for maximum Tensile strength

\begin{tabular}{|c|c|c|c|}
\hline \multirow{2}{*}{$\begin{array}{c}\text { Parocess } \\
\text { Parameters }\end{array}$} & \multicolumn{2}{|c|}{$\begin{array}{c}\text { Optimization } \\
\text { reinforcements for Tensile } \\
\text { Strength }\end{array}$} \\
\cline { 2 - 3 } & Levels & $\begin{array}{l}\text { Optimum } \\
\text { value } \\
\text { (wt\%) }\end{array}$ & $\begin{array}{l}\text { Tensile } \\
\text { strength } \\
\text { (MPa) }\end{array}$ \\
\hline $\begin{array}{c}\text { Volume fraction of } \\
\text { sisal fiber (\%) }\end{array}$ & 20 & 15.87 & \\
\hline $\begin{array}{c}\text { Volume fraction of } \\
\text { glass fiber (\%) }\end{array}$ & 30 & 23.805 & \multirow{2}{*}{37.87} \\
\hline $\begin{array}{c}\text { Volume fraction } \\
\text { of alumina (\%) }\end{array}$ & 3 & 2.38 & \\
\hline
\end{tabular}

In this Experiment $\mathrm{S} / \mathrm{N}$ ratio for 'Larger the better 'is used to design the experiment. Below Table 6 shows the response Table.

Table 6: Response table of S/N Ratio for tensile strength

\begin{tabular}{|c|c|c|c|c|}
\hline $\begin{array}{l}\text { Experimen } \\
\text { t number }\end{array}$ & $\begin{array}{l}\text { Level } \\
\text { s (A) }\end{array}$ & $\begin{array}{l}\text { Level } \\
\text { s (B) }\end{array}$ & $\begin{array}{l}\text { Level } \\
\mathrm{s}(\mathrm{C})\end{array}$ & $\mathrm{S} / \mathrm{N}$ ratio \\
\hline 1 & 1 & 1 & 1 & $\begin{array}{c}29.414 \\
1\end{array}$ \\
\hline 2 & 1 & 2 & 2 & $\begin{array}{c}31.565 \\
9\end{array}$ \\
\hline 3 & 1 & 3 & 3 & $\begin{array}{c}29.677 \\
4\end{array}$ \\
\hline 4 & 2 & 1 & 2 & $\begin{array}{c}29.099 \\
9\end{array}$ \\
\hline 5 & 2 & 2 & 3 & $\begin{array}{c}29.637 \\
4\end{array}$ \\
\hline 6 & 2 & 3 & 1 & $\begin{array}{c}28.252 \\
6\end{array}$ \\
\hline 7 & 3 & 1 & 3 & $\begin{array}{c}24.730 \\
7\end{array}$ \\
\hline 8 & 3 & 2 & 1 & $\begin{array}{c}28.175 \\
0\end{array}$ \\
\hline 9 & 3 & 3 & 2 & $\begin{array}{c}29.908 \\
1\end{array}$ \\
\hline
\end{tabular}

The analysis is made using the popular software specifically used to design of experiment applications known as MINITAB 19. Before any attempt is made to use this simple model as a predictor for the measure of performance, the possible interactions between the control factors must be considered. Thus factorial design incorporates a simple means of testing for the presence of the interaction effects. Analysis of the result leads to the conclusion that factors combination of A2, $\mathrm{B} 2$ and $\mathrm{C} 2$ gives maximum tensile strength. As for maximization of tensile strength is concerned factors A, $\mathrm{C}$ have significant effect whereas factor $\mathrm{B}$ has least as shown in Table 7.

Table 7: $\mathrm{S} / \mathrm{N}$ ratio values for tensile strength by factor level Response Table for Signal to Noise Ratios Larger is better

\begin{tabular}{|c|c|c|c|}
\hline Level & $\begin{array}{c}\text { SISAL } \\
\text { FIBER }\end{array}$ & $\begin{array}{c}\text { GLASS } \\
\text { FIBER }\end{array}$ & ALUMINA \\
\hline 1 & 30.22 & 27.75 & 28.61 \\
\hline 2 & 29.00 & 29.79 & 30.19 \\
\hline 3 & 27.60 & 29.28 & 28.02 \\
\hline
\end{tabular}




\begin{tabular}{|c|c|c|c|}
\hline Delta & 2.61 & 2.04 & 2.18 \\
\hline Rank & 1 & 3 & 2 \\
\hline
\end{tabular}

The main effect plot for $\mathrm{S} / \mathrm{N}$ ratio for all the three Factors is plotted using MINITAB 19 Software and the factors provide the optimum result will be identified as shown in Figure 5.

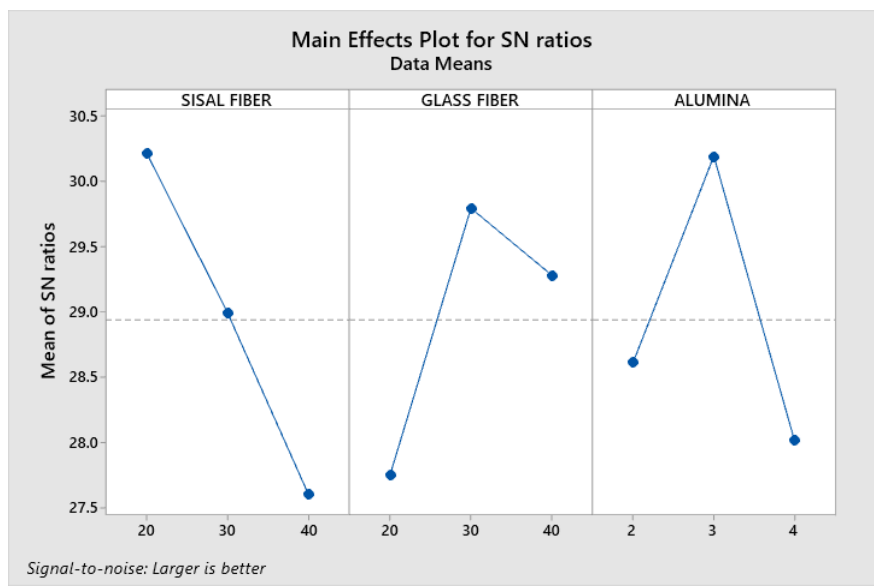

Figure 5: Main effects plot for $\mathrm{S} / \mathrm{N}$ ratios for tensile strength

The improved tensile strength, the composition of reinforcements used to include sisal fiber, glass fiber and alumina particle are optimized based on Taguchi technique. After determining the range of reinforcements from compliance testing, using Design of Experiments L9 Orthogonal array was selected.

\section{B. Empirical relation to determine predicted values of output characteristics based on $\mathrm{S} / \mathrm{N}$ ratio plots}

For validating the Taguchi predicted optimum conditions, conformation tests need to be performed. The predicted $\mathrm{S} / \mathrm{N}$ ratio $(\varepsilon)$ was used to estimate and verify the response at predicted optimum cutting conditions and it was calculated by using Eqn. 4

$$
\varepsilon \text { predicted }=\varepsilon 1+\sum_{i=1}^{x}(\varepsilon \circ-\varepsilon 1) \text {. }
$$

Where

$\varepsilon_{1}=$ Total mean $\mathrm{S} / \mathrm{N}$ ratio

$\varepsilon_{0}=$ Mean $\mathrm{S} / \mathrm{N}$ ratio at optimal level

$\mathrm{X}=$ No. of input process parameters

At the Taguchi predicted optimum conditions, the conformation experiments were performed and results were shown in Table 5 for tensile respectively. The predicted optimum conditions for tensile gives an improvement in the performance characteristic results. From Table 8 it was observed that $\mathrm{S} / \mathrm{N}$ ratios of predicted and optimal condition are very close for tensile strength. The $\mathrm{S} / \mathrm{N}$ ratio improvement found at the optimal condition for maximum tensile strength are 37.87 MPa.

From the conformation experiments, it was found that the Taguchi predicted optimum conditions of gives favourable results over the initial parameter conditions. From the Taguchi predicted optimum cutting conditions, maximum tensile strength improvement found to be $1.53 \%$ and improvement in S/ when compared to initial parameter conditions. Therefore, the Taguchi predicted optimum conditions were taken as the optimum conditions for obtaining the high tensile strength in better properties under the given conditions.

\section{Table 8 : Conformation test results for Tensile} strength

\begin{tabular}{|l|l|l|}
\hline & Prediction & Experimental \\
\hline Level & $\mathrm{A} 2 \mathrm{~B} 2 \mathrm{C} 2$ & $\mathrm{~A} 2 \mathrm{~B} 2 \mathrm{C} 2$ \\
\hline S/N Ratio & 31.1005 & 31.5659 \\
\hline Tensile Strength & 36.34 & 37.87 \\
\hline $\begin{array}{l}\text { Improvement in S/N } \\
\text { ratio }\end{array}$ & $0.46 \%$ \\
\hline $\begin{array}{l}\text { Percentage increases in } \\
\text { UTS }\end{array}$ & 1.53 \\
\hline
\end{tabular}

\section{B. ANOVA of Tensile strength.}

In order to understand a reinforcement composition of tensile strength of various factors and their interactions, it is desirable to develop analysis of variance (ANOVA) table to find out the order of significant factors as well as interactions. Table shows the results of the ANOVA with the tensile strength. From the Table 9 we can observed that the volume fractions of $\operatorname{sisal}(\mathrm{p}=0.240)$, glass $(0.324)$ and alumina( $(0.30)$ have great influence on tensile strength[18].

Table 9: ANOVA test results for the average tensile strength

\begin{tabular}{|l|c|l|l|l|l|l|}
\hline Source & D & $\begin{array}{l}\text { Seq } \\
\text { SS }\end{array}$ & $\begin{array}{l}\text { Adj } \\
\text { SS }\end{array}$ & $\begin{array}{l}\text { Adj } \\
\text { MS }\end{array}$ & F & P \\
\hline SISAL & 2 & $\begin{array}{l}10.26 \\
8\end{array}$ & $\begin{array}{l}10.26 \\
8\end{array}$ & $\begin{array}{l}5.13 \\
4\end{array}$ & $\begin{array}{l}3.1 \\
6\end{array}$ & $\begin{array}{l}0.24 \\
0\end{array}$ \\
\hline GLASS & 2 & 6.788 & 6.788 & $\begin{array}{l}3.39 \\
4\end{array}$ & $\begin{array}{l}2.0 \\
9\end{array}$ & $\begin{array}{l}0.32 \\
4\end{array}$ \\
\hline $\begin{array}{l}\text { ALUMIN } \\
\text { A }\end{array}$ & 2 & 7.582 & 7.582 & $\begin{array}{l}3.79 \\
1\end{array}$ & $\begin{array}{l}2.3 \\
3\end{array}$ & $\begin{array}{l}0.30 \\
0\end{array}$ \\
\hline $\begin{array}{l}\text { Residual } \\
\text { Error }\end{array}$ & 2 & 3.251 & 3.251 & $\begin{array}{l}1.62 \\
5\end{array}$ & & \\
\hline Total & 8 & & & \multicolumn{7}{|l}{} \\
\hline
\end{tabular}


The critical value (5\% of level of significance) from the f-tables is $F_{2,4}=6.94$ and since both of the calculated $\mathrm{f}$ values are less than 6.94, we conclude that we do not have sufficient evidence to reject either null hypothesis

\section{Regression Analysis for tensile strength}

Problems in engineering often involve the exploration of the relationship(s) between two or more variables. The relationship(s) between variables are of interest to engineers who may wish to determine the degree of association existing between independent and dependent variables. Knowing this often helps engineers to make predictions and, on this basis, to forecast and plan. Essentially, regression analysis provides a sound knowledge base from which accurate estimates of the values of a dependent variable may be made once the values of related independent variables are known. It is worth noting that in practice the choice of independent variable(s) may be made by the engineer on the basis of experience and/or prior knowledge since this may indicate to the engineer which independent variables are likely to have a substantial influence on the dependent variable. In summary, we may state that the principle objectives of regression analysis are: (a) to enable accurate estimates of the values of a dependent variable to be made from known values of a set of independent variables; (b) to enable estimates of errors resulting from the use of a regression line as a basis of prediction. Note that if a regression line is represented as $y=f(x)$ where $\mathrm{x}$ is the independent variable, then the actual function used (linear, quadratic, higher degree polynomial etc.) may be obtained via the use of a theoretical analysis or perhaps a scatter diagram (see below) of some real data. Note that a regression line represented as $y=f(x)$ is called a regression line of $y$ on $\mathrm{x}$. The Minitab software was used to formulate the regression equations (5) that predict the average response of tensile strength and tensile strength of the hybrid composite as a function of processing parameters (sisal fiber, glass fiber and alumina). The levels of the process parameters used in the regression model and their corresponding codes are shown in Figure 6 [19].

Regression Analysis: UTS Mpa versus sisal, glass, alumina

UTS Mpa= 35.7 - 0.396 SISAL + 0.205 GLASS - 0.50 ALUMINA R-

$\mathrm{sq}=\mathbf{8 8 . 3 4 \%}$
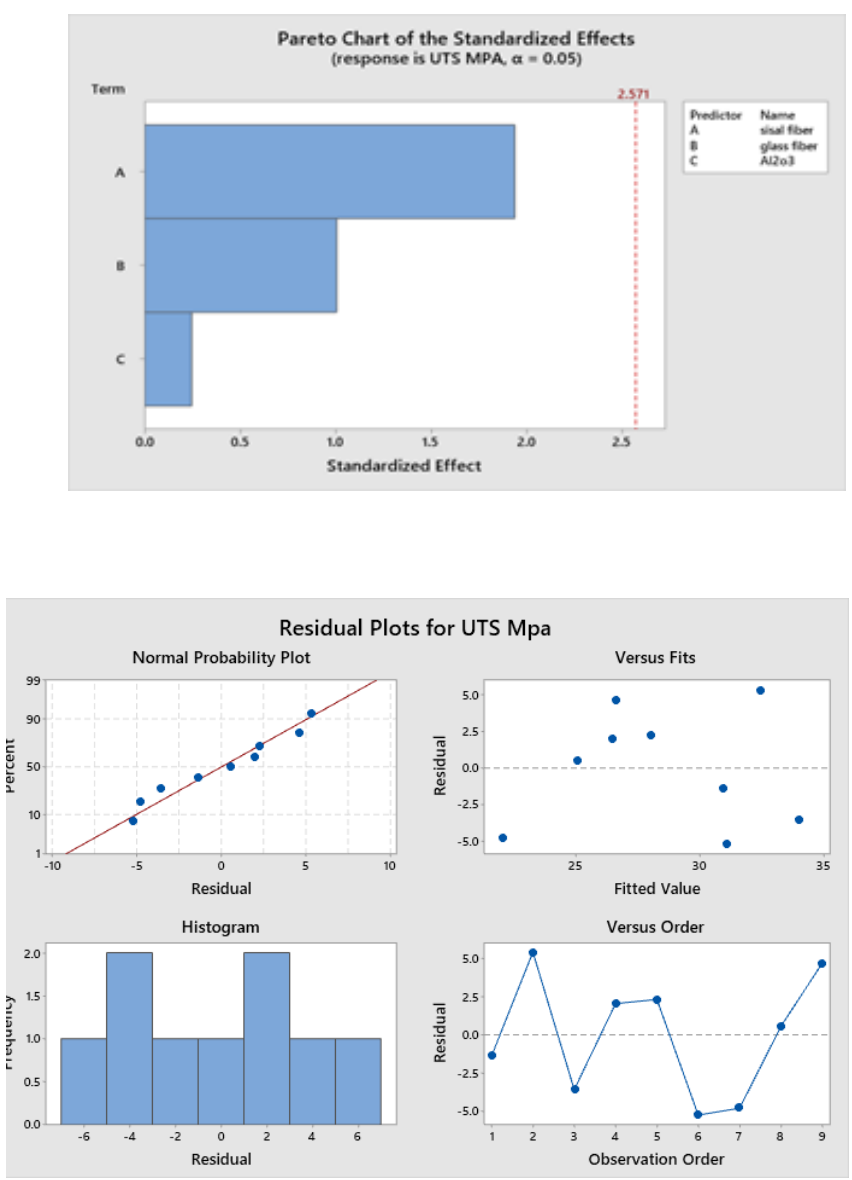

Figure 6: Regression analysis for Tensile strength v/s sisal fiber, glass fiber, alumina

The tensile strength of the predicted by regression model are compared with experimental results with the different weight percentages of fibers and alumina reinforcement in epoxy resin as in Fig 6.

It is observed that the maximum error $1.53 \%$ for regression model when compared to experimental results which shows better agreement with experimental results for L2 of hybrid composite.

Finally, the regression analysis found for tensile strength is above $75 \%$, therefore the experimental results are accepted.

\section{CONCLUSIONS.}

In the present research, an application of Taguchi and regression analysis by ANOVA for selecting optimum combination of hybrid composite laminates with different wt.\% of fiber, Alumina and matrix to study the strength. The conclusion of present study was drawn as follows. 
- $\quad$ Tensile strength of composites was estimated as per ASTM standard to know the tensile characteristics. It is observed from the results that glass-polyester (L2) composite laminate exhibits better tensile strength as compared to other composite laminates.

- Enhancement in the tensile strength is due to better bonding, adhesion and uniform dispersion of the fiber in the matrix. Composite laminates fabricated L7 and L6 exhibits lower tensile strength due to the presence of pores at the interface between the fiber and the matrix and the weak interfacial adhesion.

- Further, L3 and L9 hybrid composite laminates exhibits better tensile strength as compared to L4 and L8. it is also observed that the hybrid composite laminates L2 and L9 hybrid composites laminates exhibits better tensile properties compared to L1, L3, L4 and L5 laminates. Use of natural (sisal) fibers, synthetic (glass) fibers along with alumina enhances mechanical properties, hence use of natural fiber in the manufacturing of composite laminates increases the biodegradability and ease of disposal at the end of their service life without harming the environment. Continues use of natural fibres reinforced composite minimizes cost of production.

- Optimum condition combination for obtaining the high Tensile strength was found as sisal fiber $=20 \%$ volume fraction, glass fiber $=$ $30 \%$ volume fraction and alumina $=3$ volume fraction (L2) using Taguchi method and it was observed that $1.53 \%$ improvement of tensile strength was found at the Taguchi determined optimum cutting condition.

- From the ANOVA, it was observed that tensile strength and tensile strength significantly affected with a contribution of $1.53 \%$, followed by tensile strength.

- With respect to formability the following process can be adopted to manufacturing the component using the developed composite material.

\section{REFERENCES}

[1]. Silva, G., Kim, S., Bertolotti, B., Nakamatsu, J., \& Aguilar, R. (2020). Optimization of a reinforced geopolymer composite using natural fibers and construction wastes. Construction and Building Materials, 258.

https://doi.org/10.1016/j.conbuildmat.2020.1196 97

[2]. Yi, X. S. (2017). An introduction to composite materials. In Composite Materials Engineering (Vol. 1). https://doi.org/10.1007/978-981-105696-3_1

[3]. Ngo, T.-D. (2020). Introduction to Composite Materials. In Composite and Nanocomposite Materials - From Knowledge to Industrial Applications.

https://doi.org/10.5772/intechopen.91285

[4]. Abramovich, H. (2017). Introduction to composite materials. In Stability and Vibrations of Thin-Walled Composite Structures. https://doi.org/10.1016/B978-0-08-1004104.00001-6

[5]. Abramovich, H. (2017). Introduction to composite materials. In Stability and Vibrations of Thin-Walled Composite Structures. https://doi.org/10.1016/B978-0-08-1004104.00001-6

[6]. Peças, P., Carvalho, H., Salman, H., \& Leite, M. (2018). Natural fibre composites and their applications: A review. Journal of Composites Science, 2(4). https://doi.org/10.3390/jcs2040066

[7]. Rahman, R., \& Putra, S. Z. F. S. (2018). Tensile properties of natural and synthetic fiberreinforced polymer composites. In Mechanical and Physical Testing of Biocomposites, FibreReinforced Composites and Hybrid Composites. https://doi.org/10.1016/B978-0-08- 1022924.00005-9

[8]. Thomason, J. L. (2019). Glass fibre sizing: A review. In Composites Part A: Applied Science and Manufacturing (Vol. 127). https://doi.org/10.1016/j.compositesa.2019.1056 19

[9]. Satyanarayana, K. G., Sukumaran, K., Mukherjee, P. S., Pavithran, C., \& Pillai, S. G. K. (1990). Natural fibre-polymer composites. 
Cement and Concrete Composites, 12(2). https://doi.org/10.1016/0958-9465(90)90049-4

[10]. S.S. Munawar, K. Umemura, S. Kawai. Characterization of the morphological,physical, and chemical properties of seven nonwood plant fibre bundles. Journal ofWood Science 2007; 53:108-113

[11]. N. Abilash1, M. Sivapragash. Tensile and Compressive Behaviour of Treated Sisal and Jute Fiber Blended Polypropylene Composite.Journal of Polymer and Biopolymer Physics Chemistry, Vol. 1, No. 1, 1-8, 2013.

[12]. Kuruvilla Joseph, Romildo Dias TolêdoFilho, Beena James, Sabu Thomas \& Laura Hecker de Carvalho. A review on sisal fiber reinforced polymer composites.RevistaBrasileira de EngenhariaAgrícola e Ambiental, v.3, n.3, p.367-379, 1999

[13]. Andressa Cecília Milanese, Maria OdilaHilárioCioffi, Herman Jacobus Cornelis Voorwald. Tensile behavior of Sisal/Castor oilBased Polyurethane and Sisal/Phenolic Composites. São Carlos Mat. Res. vol.15 no.2 2012.

[14]. M.Ramesha,, K.Palanikumarb, K.Hemachandra Reddy, Comparative Evaluation on Properties of Hybrid Glass Fiber- Sisal/Jute Reinforced Epoxy Composites, Chemical, Civil and Mechanical Engineering Tracks of 3rd Nirma University International Conference, Procedia Engineering 51 ( 2013 ) $745-750$

[15]. Min Zhi Ronga,b,*, Ming Qiu Zhangb, Yuan Liub, Gui Cheng Yangb, Han Min Zengb, The effect of fiber treatment on the mechanical properties of unidirectional sisal-reinforced epoxy composites, Composites Science and Technology 61 (2001) 1437-1447.

[16]. M. Boopalan \& M. J. Umapathy \& P. Jenyfer, A Comparative Study on the Mechanical Properties of Jute and Sisal Fiber Reinforced Polymer Composites, Silicon (2012) 4:145- 149, DOI 10.1007/s12633-012-9110-6.
[17]. Saioa Garbizu, Rodrigo Llano-Ponte, In aki Mondragon, Surface Modification of Sisal Fibers: Effects on the Mechanical and Thermal Properties of Their Epoxy Composites, POLYM. COMPOS., 26:121-127, 2005. (C) 2005 Society of Plastics Engineers

[18]. Analysis of variance, workbook 44, HELM, Mathematics Education Centre, Loughborough University, Loughborough, LE11 3TU. Web: http://helm.lboro.ac.uk

[19]. Regression and correlation, workbook 43, HELM, Mathematics Education Centre, Loughborough University, Loughborough, LE11 3TU. Web: http://helm.lboro.ac.

\section{Cite this article as :}

Veenapani R, B M Rajaprakash, Akash M, "Optimization for Tensile Strength of Sisal Fiber, Glass Fiber and Alumina- Based Hybrid Composite using Taguchi Technique", International Journal of Scientific Research in Science and Technology (IJSRST), Online ISSN : 2395-602X, Print ISSN : 23956011, Volume 8 Issue 5, pp. 299-308, SeptemberOctober 2021. Available at doi : https://doi.org/10.32628/IJSRST218544 Journal URL : https://ijsrst.com/IJSRST218544 